\title{
DESAFÍOS DEL ESPAÑOL JURISDICCIONAL ESTUDIO SOBRE LA (IM)POSIBILIDAD DE EQUIVALENCIA EN LA TRADUCCIÓN DE LAS RESOLUCIONES ESPAÑOLAS AL POLACO
}

Ewa Urbańczyk

Universidad de Varsovia

http://dx.doi.org/10.18778/8220-201-4.31

\section{Resumen}

El presente trabajo se centra en los problemas dimanantes de la traducción de las resoluciones judiciales españolas al polaco, enfocándose en particular en las características específicas del español jurisdiccional entendido como una variante del español jurídico, conforme con la definición de Alcaraz Varó y Hughes (2008). En el artículo se comentarán los términos más problemáticos y la complejidad de las decisiones traductológicas resultante de la asimetría entre el idioma de origen y el idioma meta o de las diferencias entre los sistemas legales de ambos países. El fin de trabajo será intentar responder a la pregunta si en la traducción jurídica se puede hablar de la equivalencia.

Palabras clave: Traducción jurídica, español jurisdiccional, equivalencia. 


\section{¿Español jurídico o español jurisdiccional?}

El propósito del presente trabajo consiste en analizar la problemática de la equivalencia terminológica en la traducción jurídica a partir del ejemplo de la resolución judicial española traducida al polaco. El estudio se basará en el análisis de la sentencia elegida de la base de datos de las sentencias del Consejo General del Poder Judicial (CENDOJ: Buscador de Sistema de Jurisprudencia).

Sin embargo, no es posible entrar en los detalles de la temática mencionada sin determinar previamente cómo entendemos el lenguaje en el que están redactadas las sentencias españolas. No es una tarea fácil, puesto que en el ámbito de los estudios hispánicos no se puede hablar de una sola división de los tipos de los textos que abarquen el tema de Derecho y, por consiguiente, tampoco de los lenguajes dimanantes de estos ${ }^{1}$. Para los objetivos del presente artículo nos basaremos en la tipología de Alcaraz Varó y Hughes (2008) incluida en el libro El español jurídico, en el que dichos autores clasifican el español jurídico como una lengua de especialidad, señalando además que es una de sus variantes más significativas (Alcaraz Varó y Hughes, 2008: 15-16). Dentro del español jurídico, percibido como la categoría principal, los autores distinguen sus cuatro variantes: el español legislativo, jurisdiccional o de los jueces, el administrativo y el español notarial (Alcaraz Varó y Hughes 2008: 17). El español de las resoluciones judiciales en este trabajo será entonces entendido como español jurisdiccional. Dentro de sus rasgos principales destacan: una terminología, construcciones sintácticas y estilísticas muy especiales, así como el hecho de que su empleo está vinculado a unos géneros propios (tales como la sentencia) (Alcaraz Varó y Hughes, 2008: 16-17). En nuestro trabajo nos enfocaremos principalmente

1 Por ejemplo, algunos investigadores no distinguen entre los textos de carácter administrativo y jurídico, considerando que ambos géneros tienen calidades parecidas y, en consecuencia, que la frontera entre ellos no puede ser determinada con claridad (Gutiérrez Arcones, 2015: 145). 
en la primera y en la última de las mencionadas características: al haber seleccionado un género específico, las sentencias judiciales, analizaremos su vocabulario, centrándonos en los términos que, a nuestro parecer, pueden resultar problemáticos.

\section{2.}

\section{¿Qué significa equivalencia en la traducción jurídica?}

En la búsqueda de la posible equivalencia nos guiaremos por la opinión de Gutiérrez Arcones (2015: 152) que señala que "los textos jurídicos solo se entienden dentro de una cultura, o mejor dicho, de un ordenamiento jurídico". Esta consideración indica asimismo la complejidad de este tipo de la traducción especializada que requiere no solamente los conocimientos puramente lingüísticos sino también un conocimiento del sistema legal de los dos países.

Pešková (2015: 129) opina que en los textos especializados se pueden distinguir los asíllamados "componentes constantes y componentes potenciales". Primeros son constituidos por la terminología sin la cual no se puede hablar de un texto especializado. Los "potenciales" son los estilísticamente marcados, que aunque no sean imprescindibles, predominan en estos textos, sirviendo como marcadores de su estilo. Ambos tipos de componentes constituyen dificultades en la traducción. Al plantear la cuestión de la equivalencia, la misma autora distingue sus tres tipos: total, parcial y nula (Pešková, 2015: 132). En el presente artículo intentaremos analizar unos componentes constantes y la (im)posibilidad de su traducción al polaco. 


\section{La muestra del análisis de una sentencia}

La resolución elegida es una sentencia dictada por la Audiencia Nacional en el procedimiento penal (apelación en procedimiento abreviado). Los problemas traductológicos vinculados a la búsqueda de la equivalencia terminológica empiezan ya con el nombre del órgano que emitió la sentencia analizada. Son propiamente las construcciones onímicas, tales como los mencionados nombres de los órganos, instituciones, entidades estatales, que constituyen uno de los problemas fundamentales en la traducción jurídica (Popek-Bernat, Gołębiewska, 2016: 143). ¿Cómo lograr la equivalencia de algo que no existe en la realidad del lenguaje de cultura meta? Estamos de acuerdo con Lobato Patricio que estima que la equivalencia de los términos se la puede establecer mediante la definición: si la explicación de algún término corresponde con su definición en otro idioma, dichos términos podrían traducirse uno por el otro: podrían considerarse equivalentes (Lobato Patricio, 2009: 193). No obstante, en caso de español y polaco, muchas veces no se puede hablar de la equivalencia por motivos culturales. No es posible sustituir un término relativo a algún órgano judicial concreto si este no existe en ambos países.

En la resolución seleccionada ${ }^{2}$ aparecen los siguientes nombres de los órganos judiciales, mostrados en la tabla.

Tabla 1. Órganos judiciales. Elaboración propia.

\section{ÓRGANO JUDICIAL}

Audiencia Nacional

Juzgado Central de lo Penal $n^{\circ} 1$ de Madrid

Juzgado Central de Instrucción $n^{\circ} 4$

2 La resolución seleccionada puede consultarse en la página del CENDOJ, http://www.poderjudicial.es/search/contenidos.action?action=contentpdf\&databasematch $=$ AN\&reference $=8372290 \&$ links $=\& o p-$ timize $=20180507 \&$ publicinterface $=$ true [fecha de consulta: 29.01.2019]. 
Dado que el sistema judicial español y polaco no pueden ser considerados completamente comparables, en Polonia no existen equivalentes de los citados juzgados y tribunales. Aunque el objetivo del presente trabajo no está enfocado en el derecho comparativo, nos parece apropiado indicar las principales diferencias en la organización de jurisdicción en España y en Polonia para demostrar las dificultades traductológicas vinculadas a los nombres de los órganos que aparecen en la sentencia.

En España la organización de Juzgados y Tribunales está regulada por la Ley Orgánica 6/1985, de 1 de julio, del Poder Judicial, según la cual la jurisdicción ordinaria se divide en cuatro órdenes jurisdiccionales:

- civil,

- penal,

- contencioso-administrativo,

- social.

Además de los mencionados cuatro, órdenes existe la Jurisdicción Militar (https://www.boe.es/buscar/act.php?id=BOE-A-1985-12666\# [fecha de consulta: 29.01.2019]).

La organización jurisdiccional polaca está regulada en el capítulo VIII de la Constitución. Dentro de los órganos de administración de justicia se distinguen los siguientes:

- Sąd Najwyższy [Tribunal Supremo] $]^{3}$,

- sądy powszechne [jurisdicción ordinaria],

- sądy administracyjne [jurisdicción contencioso-administrativa]

- y sądy wojskowe [tribunales militares].

La jurisdicción ordinaria corresponde a los

- sądy apelacyjne [tribunales de apelación],

- sądy okręgowe [tribunales regionales],

- sądy rejonowe [tribunales de distrito].

3 Las propuestas traductológicas de los nombres de los órganos judiciales polacos al español provienen de la autora del presente trabajo y están basadas en el diccionario de Komarnicki et. alii (2010): Słownik terminologii prawniczej hiszpańsko-polski polsko-hiszpański y en el contenido de la página del Portal Europeo de e-Justicia disponible en https://e-justice.europa.eu/content_judicial_systems_ in_member_states-16-pl-es.do [fecha de consulta: 29.01.2019]. 
La jurisdicción contencioso-administrativa corresponde a Naczelny Sąd Administracyjny [Tribunal Superior de lo Contencioso-Administrativo], así como a los wojewódzkie sądy administracyjne [tribunales regionales de lo contencioso-administrativo]. El máximo órgano jurisdiccional, que no es considerado un tribunal ordinario, es el Sąd Najwyższy. Otros tribunales no ordinarios son Trybunał Konstytucyjny [Tribunal Constitucional] y Trybunał Stanu [Tribunal de Estado] (http://www.sejm.gov.pl/prawo/ konst/polski/kon1.htm [fecha de consulta: 29.01.2019]).

De acuerdo con la jurisdicción española, el órgano que dictó la sentencia examinada en el presente trabajo, es decir, la Audiencia Nacional, es

un órgano jurisdiccional único en España con jurisdicción en todo el territorio nacional, constituyendo un Tribunal centralizado y especializado para el conocimiento de determinadas materias que vienen atribuidas por Ley (http://www. poderjudicial.es/cgpj/es/Poder-Judicial/Audiencia-Nacional/ Informacion-institucional/Que-es-la-AN/ [fecha de consulta: 29.01.2019]).

Puesto que en Polonia no existe un órgano que tenga las mismas responsabilidades, la solución más adecuada nos parece la traducción por explicación. El Portal Europeo de e-Justicia como traducción de Audiencia Nacional al polaco propone Krajowy Sąd Karny i Administracyjny (literalmente: Tribunal Nacional de lo Penal y Contencioso-Administrativo), lo que supone una traducción fiel en cuanto a las funciones que este tribunal desempaña en España. Es interesante que uno de los diccionarios jurídicos polacos más populares, esto es, Słownik terminologii prawniczej de Komarnicki presente la siguiente explicación del papel de la Audiencia Nacional sin ofrecer una traducción específica:

Audiencia Nacional (prawo hiszp.) trybunał o zasięgu krajowym z siedzibą w Madrycie (nie rozstrzyga spraw cywilnych i wojskowych) (Komarnicki et. alii, 2010: 22) 
En lo que se refiere a otros dos órganos mencionados en la resolución, a saber, el Juzgado Central de lo Penal $n^{\circ} 1$ de Madrid y el Juzgado Central de Instrucción $\mathrm{n}^{\circ} 4$, sus equivalentes tampoco existen en Polonia. A la hora de traducir el traductor tiene que ser consciente de su función. De acuerdo con la enciclopedia jurídica,

(...) estos Juzgados conocerán del enjuiciamiento de los delitos que están previstos para que, en primera instancia, sean de la competencia de la Audiencia Nacional, y siempre que el referido enjuiciamiento se tramite por los cauces del procedimiento abreviado. También con sede en Madrid y jurisdicción en toda España, los Juzgados Centrales de Instrucción instruirán las causas tramitadas conforme al procedimiento abreviado y cuyo enjuiciamiento corresponda a los Juzgados centrales de lo penal o a la Sala de lo Penal de la Audiencia Nacional (http://www.enciclopedia-juridica.biz14.com/d/juzgados-centrales-de-lo-penal/juzgados-centrales-de-lo-penal.htm [fecha de consulta: 29.01.2019]).

En este caso la solución más adecuada nos parece la traducción literal. Los nombres españoles de dichos órganos se refieren a sus funciones y al alcance de sus responsabilidades. Por consiguiente, se podrían traducir literalmente: Centralny Sąd ds. Karnych y Centralny Sąd Śledczy.

Tabla 2. Órganos judiciales: propuesta de traducción. Elaboración propia.

\section{ÓRGANO JUDICIAL ESPAÑOL}

Juzgado Central de lo Penal no 1 de Madrid

Juzgado Central de Instrucción no 4

\section{TRADUCCIÓN AL POLACO}

Centralny Sąd ds. Karnych nr 1 w Madrycie

Centralny Sąd Śledczy nr 4

La comentada traducción, según Pešková (2015), se podría clasificar como un ejemplo de la equivalencia nula. Sin embargo, aunque los sistemas judiciales de España y Polonia presentan muchas diferencias, aun en la sentencia seleccionada se pueden encontrar 
ejemplos de los términos que en la traducción tendrían sus equivalentes parciales o totales. Un buen ejemplo es la figura del procurador de los tribunales. Según la enciclopedia jurídica, es

persona que ejerce la representación legal de las partes en todo tipo de procesos judiciales (...). Para la obtención del título profesional de procurador es imprescindible estar colegiado en el Colegio Profesional de Procuradores, y podrán obtener dicho título las personas que se encuentren en posesión del título de licenciado en derecho, o título de grado equivalente, y superen la formación y evaluación establecidas por la ley (http://www. enciclopedia-juridica.biz14.com/d/procurador-de-los-tribunales/procurador-de-los-tribunales.htm [fecha de consulta: 29.01.2019]).

Este término suele ser traducido al polaco como 'pełnomocnik procesowy'4. En el derecho polaco el 'pełnomocnik procesowy' (literalmente 'apoderado procesal') como término aparece solamente en el procedimiento civil. Sus funciones están comprendidas en el Kodeks Postępowania Cywilnego [Código de Procedimiento Civil]. Es necesario señalar que 'pełnomocnik procesowy' en Polonia puede ser no solamente una persona con formación académica en materia de derecho, sino también el cónyuge, los hermanos, los ascendentes y descendientes de la parte (http:// prawo.sejm.gov.pl/isap.nsf/download.xsp/WDU19640430296/U/ D19640296Lj.pdf: 21-22 [fecha de consulta: 29.01.2019]). En el procedimiento penal se habla solamente de 'pełnomocnik' o de 'pełnomocnik strony' (literalmente en español 'apoderado', 'apoderado de la parte') y, a diferencia del procedimiento civil, no lo pueden ser miembros de familia (http://prawo.sejm.gov.pl/isap. nsf/download.xsp/WDU19970890555/U/D19970555Lj.pdf: 26 [fecha de consulta: 29.01.2019]). El traductor debería ser consciente de estas diferencias. Pese a que el término español tiene su equivalente en polaco, no se puede hablar de la equivalencia total.

4 Se lo puede confirmar en el antes mencionado diccionario de Komarnicki et. alii (2010: 130). 
En la sentencia analizada se trata de un proceso penal. Por consiguiente, consideramos que la traducción al polaco debería abarcar el carácter del procedimiento. En consecuencia, en nuestra opinión, la adición de la palabra 'procesowy' resulta redundante, nosotros optaríamos por la traducción 'pełnomocnik strony' (apoderado de la parte).

Otro ejemplo de la búsqueda de equivalencia es el verbo 'desestimar', en la sentencia usado con referencia al recurso ('desestimar el recurso'). El traductor polaco, buscando la definición de este verbo podrá encontrar, por ejemplo, la siguiente explicación:

desestimar: denegar o rechazar las peticiones de la parte por el juez o un tribunal no hacer lugar a lo solicitado (http://www. enciclopedia-juridica.biz14.com/d/desestimar/desestimar.htm [fecha de consulta: 29.01 .2019$]$ ).

Lo que llama la atención, sin duda alguna, es el verbo 'rechazar' propuesto como el sinónimo de 'desestimar'. Este verbo en polaco es entendido sobre todo como 'no admitir' ('odrzucać'). En Polonia en el contexto de las decisiones que el juez o el magistrado puede tomar con referencia a los actos procesales tales como la demanda o en caso de un recurso procesal se distinguen principalmente dos verbos: 'oddalić' y 'odrzucić', que significan precisamente 'desestimar' y 'rechazar'. Sin embargo, no pueden ser tratados como sinónimos. El verbo 'odrzucić' significa rechazar por motivos formales, no admitir. La inadmisión también en español significa que la petición no ha sido tomada en consideración, que no ha sido valorada. 'Oddalic', a su vez, expresa el hecho de desestimar las peticiones. Tanto en español como en polaco una desestimación conlleva un estudio del caso que termina con un pronunciamiento denegatorio. El traductor polaco tiene que saber diferenciar estos verbos y ser consciente de que 'rechazar' en el contexto jurídico no necesariamente será el sinónimo de inadmitir. En caso de la sentencia analizada, con arreglo a su contenido y al significado del verbo, una traducción correcta sería 'oddalić apelację' (y no 'odrzucić'), constituyendo asimismo un ejemplo de la equivalencia total. 


\section{4.}

\section{Conclusiones}

El presente trabajo no pretende servir como fuente de equivalentes terminológicos en la traducción del español al polaco. La principal intención fue el análisis de diferentes problemas con los cuales un traductor tiene que enfrentarse a la hora de traducir, por ejemplo, los referentes culturales tales como los nombres de los órganos jurisdiccionales, de los participantes del procedimiento o de los términos especializados vinculados a las decisiones emitidas por los jueces y magistrados. Este trabajo, no obstante, se limita solamente a ofrecer soluciones inevitablemente subjetivas y parciales, ya que arbitrario es el análisis de la problemática y de los argumentos que hemos tratado.

Si bien el estudio de una sentencia y el comentario de solamente unos términos no es exhaustivo para poder sacar conclusiones firmes en el tema de la traducción jurídica y de la equivalencia, sí permite demostrar unos ejemplos de los problemas con los cuales uno tiene que enfrentarse en el proceso de traducción. En la búsqueda de la equivalencia terminológica en la sentencia analizada logramos identificar sus tres categorías: equivalencia nula, parcial y total. A modo de conclusión recopilamos sus tres ejemplos en la siguiente tabla:

Tabla 3. Ejemplos de equivalencia. Elaboración propia.

\section{\begin{tabular}{l|l|l|l|} 
TIPO DE EQUIVALENCIA & EJEMPLO DEL TEXTO ORIGINAL & POSIBLE TRADUCCIÓN
\end{tabular}}

Equivalencia nula

Audiencia Nacional

Krajowy Sąd Karny

i Administracyjny

\begin{tabular}{lll}
\hline Equivalencia parcial & procurador de los tribunales & pełnomocnik strony \\
\hline Equivalencia total & desestimar & oddalać \\
\hline
\end{tabular}

Nuestra intención ha sido sensibilizar a todos los que trabajen con este tipo de textos alrededor de la necesidad de proceder con máxima cautela: la traducción jurídica es un complejo proceso que requiere un trabajo con doble perspectiva, tomando en cuenta tanto el Derecho como las características lingüísticas del texto. 


\section{Referencias bibliográficas}

Alcaraz Varó, E., Hughes, B. (2008), El español jurídico, Barcelona: Editorial Ariel.

Consejo General del Poder Judicial, [en línea] <http://www.poderjudicial.es/search/contenidos.action?action=contentpdf\&databasematch $=$ AN\&reference $=8372290 \&$ links $=\&$ optimize $=20180507 \&$ publicinterface $=$ true $>$ [fecha de consulta: 29.01.2019].

Enciclopedia jurídica (2014), [en línea], <http://www.enciclopedia-juridica.biz14.com/inicio-enciclopedia-diccionario-juridico.html> [fecha de consulta: 29.01.2019].

Gutiérrez Arcones, D. (2015), "Estudio sobre el texto jurídico y su traducción: características de la traducción jurídica, jurada y judicial", Miscelánea Comillas, 73/142, Universidad Pontificia Comillas, 141-175.

Komarnicki, M., Komarnicka, E., Komarnicki, I. (2010), Słownik terminologii prawniczej. Hiszpańsko-polski/polsko-hiszpański, Warszawa: C.H. Beck.

Konstytucja Rzeczypospolitej Polskiej, [en línea], <http://www. sejm.gov.pl/prawo/konst/polski/kon1.html> [fecha de consulta: 29.01.2019].

Ley Orgánica 6/1985, de 1 de julio, del Poder Judicial, "Boletín Oficial del Estado”, núm. 157, de 2 de julio de 1985, [en línea], $<$ https://www.boe.es/buscar/act.php?id=BOE-A-1985-12666\#> [fecha de consulta: 29.01.2019].

Lobato Patricio, J. (2009), "La traducción jurídica, judicial y jurada: vías de comunicación con las administraciones", Entreculturas, 1, Universidad de Málaga (UMA): Departamento de Traducción e Interpretación, 191-206.

Pešková, J. (2015), "Problemas de la traducción de textos de contenido jurídico: búsqueda de los equivalentes más apropiados", Hikma: estudios de traducción = translationstudies, 14, Universidad de Córdoba: Servicio de Publicaciones, 127-140.

Popek-Bernat, K., Gołębiewska, M. (2016), “Wybrane problemy z zakresu tłumaczenia orzeczeń sądowych z języka hiszpańskiego na język polski”, en M. Czyżewska y A. Matulewska Przyszłość zawodu tłumacza przysięgłego i specjalistycznego 
- współczesne wyzwania, Warszawa: Polskie Towarzystwo Tłumaczy Przysięłych i Specjalistycznych TEPIS, 137-154.

Portal Europeo de e-Justicia, [en línea], <https://e-justice.europa. eu/home.do $>$ [fecha de consulta: 29.01.2019].

Ustawa z dnia 17 listopada 1964 r. Kodeks postępowania cywilnego, Dz.U. 1964 Nr 43 poz. 296, [en línea] <enisap.sejm.gov.pl/ Download?id=WDU19640430296\&type $=3>$ [fecha de consulta: 29.01.2019].

Ustawa z dnia 6 czerwca 1997 r. Kodeks postępowania karnego. Dz.U. 1997 nr 89 poz. 555, [en línea] <http://prawo.sejm.gov. pl/isap.nsf/download.xsp/WDU19970890555/U/D19970555Lj. pdf $>$ [fecha de consulta: 29.01.2019]. 